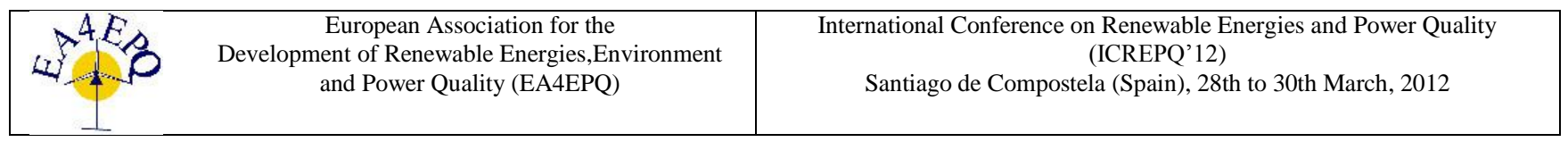

\title{
A Novel Direct Torque Control Scheme for PMSM for Improving Quality in Torque and Flux
}

\author{
A. DRAOU ${ }^{1}$, K. HARTANI $^{2}$ \\ ${ }^{1}$ Department of Electrical Engineering, University of Hail Po.Box 2440, Hail, Saudi Arabia, adraou@ yahoo.com \\ ${ }^{2}$ Department of Electrical Engineering, University Dr. Moulay Tahar of Saida, BP-138 En-Nasr, Saida, Algeria
}

\begin{abstract}
Permanent magnet synchronous motors (PMSM) are extensively used in high-performance industrial applications. The electromagnetic torque in a PMSM is proportional to the angle between the stator and rotor flux linkage, thus, high dynamic response can be achieved by means of direct torque control. The main advantage of DTC is its simple structure since no coordinate transformations or PWM generation is needed. In this paper, an improved scheme to solve the torque and the stator flux linkage ripples of direct torque control (DTC) for a permanent magnet synchronous motor is proposed. Moreover, the fuzzy DTC control strategy based on fuzzy controller using the space vector modulation (SVM) is designed and presented in this paper. Theoretical development and simulation results by the classical and improved DTC are also presented and compared to support the proposed strategy.
\end{abstract}

\section{Key words:}

PMSM DTC drives, fuzzy logic, space vector modulation

\section{Introduction}

Nowadays, a permanent magnet synchronous motor has been more popular with its simple structure, reliable operation, and especially high efficiency. PMSM are mostly applied when fast torque response and high performance are needed. Following the vector control technology, direct torque control was proposed by $\mathrm{M}$. Depenbrock and I. Takahashi for the induction motor drive in the middle of 1980s, as reported in [1].

The basic idea of DTC is to control the torque and flux linkage by selecting one of the voltage vectors generated by a VSI in order to maintain flux and torque within the limits of two hysteresis bands. The right selection of the vector voltage allows a decoupled control of flux and torque without $\mathrm{d}-\mathrm{q}$ coordinate transformation, PWM and PI current regulators that Field Oriented Control (FOC) usually need. DTC offers many advantages such as lower parameter dependency and complexity compared with the FOC, which makes the system more robust and easier to implement.

However, the major DTC system drawback is its relatively high torque ripple. Basically, the high current and torque ripple in DTC are due to the presence of hysteresis comparators together with the limited number of available voltage vector [2]. Since the introduction of the DTC, research has been carried out to solve these problems, and specially the torque ripple [3].

Recently, many researchers have devoted their research towards reducing the torque and flux ripples, as elaborated in [4]. With multi-level inverter, there will be more voltage space vectors available to control the flux and torque and a smoother electromagnetic torque can be expected. The excellent performance power switches and fixed switching frequency are required, which will accordingly increase the cost and complexity of the system.

Based on the analysis of the basic DTC theory and SVM technology, this paper proposes a fuzzy DTC strategy for PMSM. The stator flux error and the torque are reasonably fuzzified into several fuzzy subsets to optimize selection of the voltage vector. This method is remarkably different from the basic DTC. Finally, the simulation results included show that the flux and torque ripples are dramatically decreased and the method can ensure the fixed switching frequency very well.

\section{PMSM Mathematical Model}

PMSM mathematical model in $\alpha-\beta$ coordinate system is shown as follows [5-6]:

Stator flux equation :

$$
\left\{\begin{array}{l}
\Phi_{s \alpha}=L_{s} i_{s \alpha}+\Phi_{f} \cos \theta \\
\Phi_{s \beta}=L_{s} i_{s \beta}+\Phi_{f} \sin \theta
\end{array}\right.
$$

Stator voltage equation :

$$
\left\{\begin{array}{l}
v_{s \alpha}=R_{s} i_{s \alpha}+\frac{d \Phi_{s \alpha}}{d t} \\
v_{s \beta}=R_{s} i_{s \beta}+\frac{d \Phi_{s \beta}}{d t}
\end{array}\right.
$$

Torque equation :

$$
T_{e m}=\frac{3}{2} p\left(\Phi_{s \alpha} i_{s \beta}-\Phi_{s \beta} i_{s \alpha}\right)
$$

The mechanical equation is expressed by :

$$
J \frac{d \Omega}{d t}+f \Omega=T_{e m}-T_{r}
$$

where :

$$
\omega_{m}=p \Omega
$$

The basic model of the conventional DTC scheme is shown in Figure 1. The magnitude of stator flux and electromagnetic torque calculated are compared with their reference values in the hysteresis comparators shown in Figure 2 and the outputs of the comparators are fed to a switching table to select an appropriate inverter voltage vector. The switching shown in Table 1 determine the voltage vector that will be applied based on the position of the stator flux and the required changes in stator flux magnitude and torque [7]. The selected voltage vector will be applied to the PMSM motor at the end of the sample time. In VSI, there are six equally 
spaced voltage vectors having the same amplitude and two zero VSI voltage vectors as shown in Figure 3.

In DTC, torque and flux are controlled independently by selecting the optimum voltage space vector for the entire switching period and the errors are maintained within the hysteresis band [8]. In conventional DTC, only one vector is applied for the entire sampling period. So for small errors, the motor torque may exceed the upper/lower torque limit. Instead, by using more than one vector within the sampling period, the torque ripple can be reduced. The slip frequency can be controlled precisely by inserting zero vector[9]. For a smaller hysteresis band, frequency of operation of the PWM inverter could be very high. The switching frequency always varies according to the width of hysteresis band.

\begin{tabular}{|c|c|c|c|c|c|c|c|}
\cline { 3 - 8 } \multicolumn{2}{c|}{} & \multicolumn{7}{c|}{ Sector } \\
\hline$\tau_{\Phi}$ & $\tau_{c}$ & 1 & 2 & 3 & 4 & 5 & 6 \\
\hline \multirow{4}{*}{1} & 1 & $\mathrm{~V}_{2}$ & $\mathrm{~V}_{3}$ & $\mathrm{~V}_{4}$ & $\mathrm{~V}_{5}$ & $\mathrm{~V}_{6}$ & $\mathrm{~V}_{1}$ \\
\cline { 2 - 8 } & 0 & $\mathrm{~V}_{7}$ & $\mathrm{~V}_{0}$ & $\mathrm{~V}_{7}$ & $\mathrm{~V}_{0}$ & $\mathrm{~V}_{7}$ & $\mathrm{~V}_{0}$ \\
\cline { 2 - 8 } & -1 & $\mathrm{~V}_{6}$ & $\mathrm{~V}_{1}$ & $\mathrm{~V}_{2}$ & $\mathrm{~V}_{3}$ & $\mathrm{~V}_{4}$ & $\mathrm{~V}_{5}$ \\
\hline \multirow{3}{*}{0} & 1 & $\mathrm{~V}_{3}$ & $\mathrm{~V}_{4}$ & $\mathrm{~V}_{5}$ & $\mathrm{~V}_{6}$ & $\mathrm{~V}_{1}$ & $\mathrm{~V}_{2}$ \\
\cline { 2 - 8 } & 0 & $\mathrm{~V}_{0}$ & $\mathrm{~V}_{7}$ & $\mathrm{~V}_{0}$ & $\mathrm{~V}_{7}$ & $\mathrm{~V}_{0}$ & $\mathrm{~V}_{7}$ \\
\cline { 2 - 9 } & -1 & $\mathrm{~V}_{5}$ & $\mathrm{~V}_{6}$ & $\mathrm{~V}_{1}$ & $\mathrm{~V}_{2}$ & $\mathrm{~V}_{3}$ & $\mathrm{~V}_{4}$ \\
\hline
\end{tabular}

Table 1 Switching Table

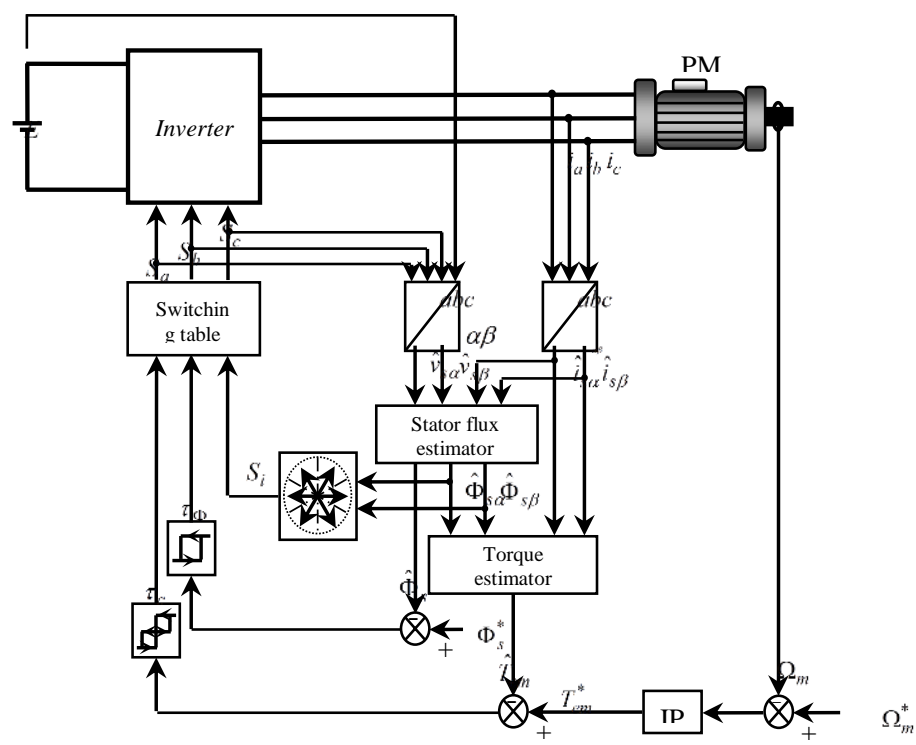

Fig. 1 Basic DTC PMSM scheme.

\section{Fuzzy Direct Torque Control}

Common disadvantages of conventional DTC are high torque ripple and slow transient response to the step changes in torque during start-up. Several techniques have been developed to improve the torque performance. One of them is based on fuzzy logic method [15]-[16] which allows to reduce the ripples considerably.

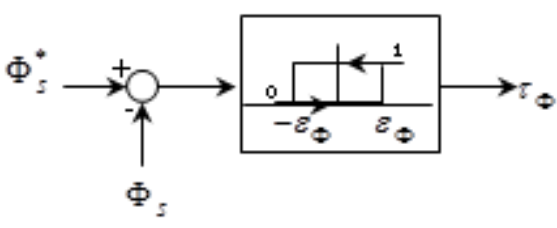

(a)

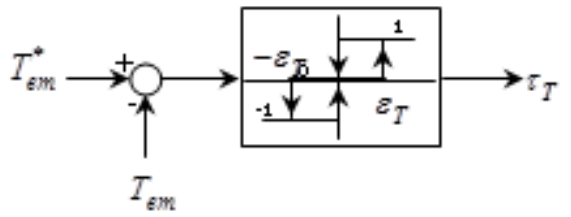

(b)

Fig. 2 Hysteresis comparator (a) torque, (b) stator flux

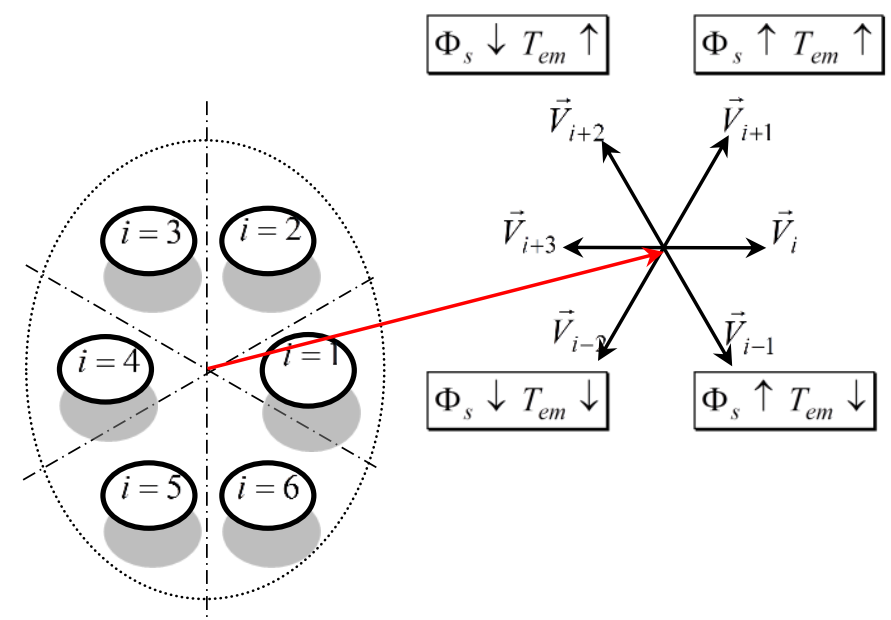

Fig. 3 Variation of the torque and flux.

Figure 4 depicts schematically a direct torque fuzzy control, in which the fuzzy controllers replace the flux linkage and torque hysteresis controllers and the switching table normally used in conventional DTC system [10]-[12].

The proposed Fuzzy DTC scheme uses the stator flux amplitude and the electromagnetic torque errors through two fuzzy logic controllers (FLC1 and FLC2). This is to generate a voltage space vector (reference voltage) by acting on both the amplitude and the angle of its components which is used by a space vector modulation to generate the inverter switching states. In Figure 6, the errors of the stator flux amplitude and the torque are selected as the inputs, and the reference voltage amplitude as the output of the fuzzy logic controller (FLC1). The increment angle as the output of the fuzzy logic controller (FLC2) that will be added to the angle of the stator flux vector and the results are delivered to the space vector modulation which calculates the switching states $S_{a}, S_{b}$ and $S_{c}$.

The mamdani's and sugeno methods are employed for the fuzzy reasoning algorithms in the FLC1 and FLC2, respectively. Figure 5 and Figure 6 illustrate the membership functions for both fuzzy logic controllers FLC1 and FLC2, respectively. 


\begin{tabular}{|c|c|c|c|c|c|c|c|}
\hline$\tilde{e}_{T}^{1} \rightarrow$ & \multirow{2}{*}{} & & & & & & \\
\cline { 1 - 6 }$\tilde{e}_{\Phi}^{1} \downarrow$ & LN & MN & SN & EZ & SP & MP & LP \\
\hline LN & LP & MP & SP & SP & SP & MP & LP \\
\hline MN & LP & MP & SP & SP & SP & MP & LP \\
\hline SN & LP & MP & SP & EZ & SP & MP & LP \\
\hline EZ & LP & MP & SP & EZ & SP & MP & LP \\
\hline SP & LP & MP & SP & EZ & SP & MP & LP \\
\hline MP & LP & MP & SP & SP & SP & MP & LP \\
\hline LP & LP & MP & SP & SP & SP & MP & LP \\
\hline \multicolumn{7}{|c}{ Table 2. FLC Rules } \\
\hline
\end{tabular}

\begin{tabular}{|c|c|c|c|c|c|c|c|c|c|}
\hline$\tilde{e}_{\Phi}^{2}$ & \multicolumn{3}{|c|}{$\mathrm{P}$} & \multicolumn{3}{c|}{$\mathrm{Z}$} & \multicolumn{3}{c|}{$\mathrm{N}$} \\
\hline$\tilde{e}_{T}^{2}$ & $\mathrm{P}$ & $\mathrm{Z}$ & $\mathrm{N}$ & $\mathrm{P}$ & $\mathrm{Z}$ & $\mathrm{N}$ & $\mathrm{P}$ & $\mathrm{Z}$ & $\mathrm{N}$ \\
\hline$\delta$ & $\frac{\pi}{4}$ & 0 & $\frac{-\pi}{4}$ & $\frac{\pi}{2}$ & $\frac{\pi}{2}$ & $\frac{-\pi}{2}$ & $\frac{3 \pi}{2}$ & $\pi$ & $\frac{-3 \pi}{4}$ \\
\hline
\end{tabular}

Table 3. Reference voltage increment angle

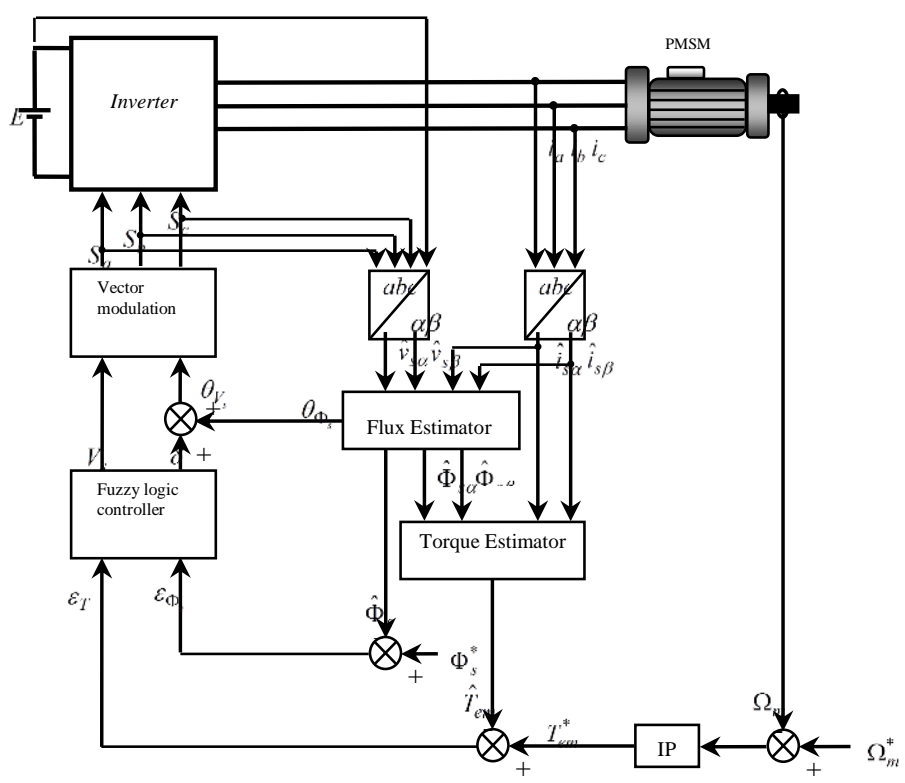

Fig. 4 Block diagram of the proposed torque ripple control of DTC

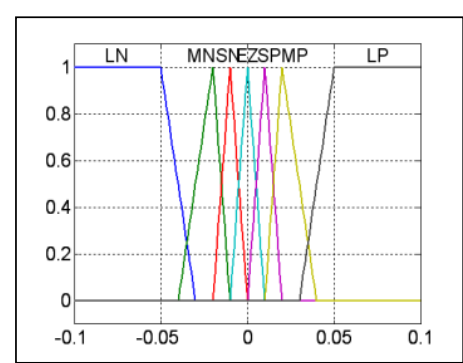

(a) Stator flux error

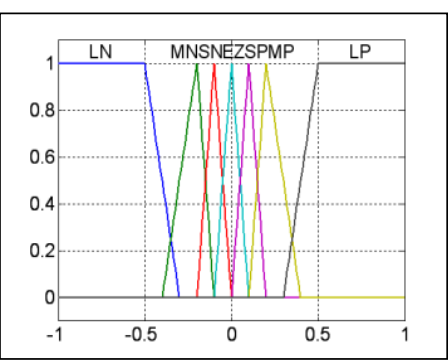

(b) Torque error

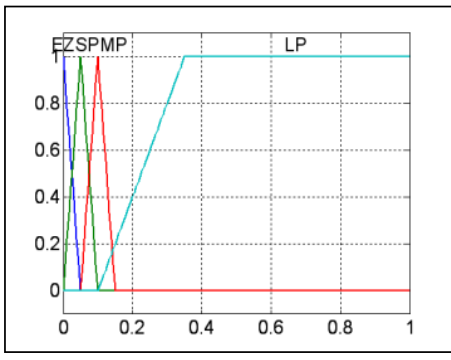

(c) Reference voltage

Fig. 5 Membership functions for the FLC1.

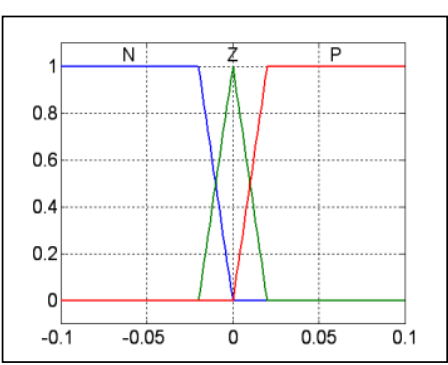

(a) Stator flux error

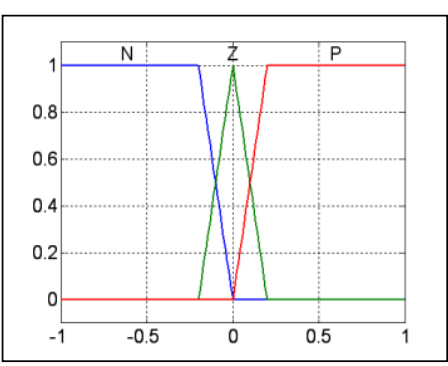

(b) Torque error

Fig. 6. Membership functions for the FLC2 


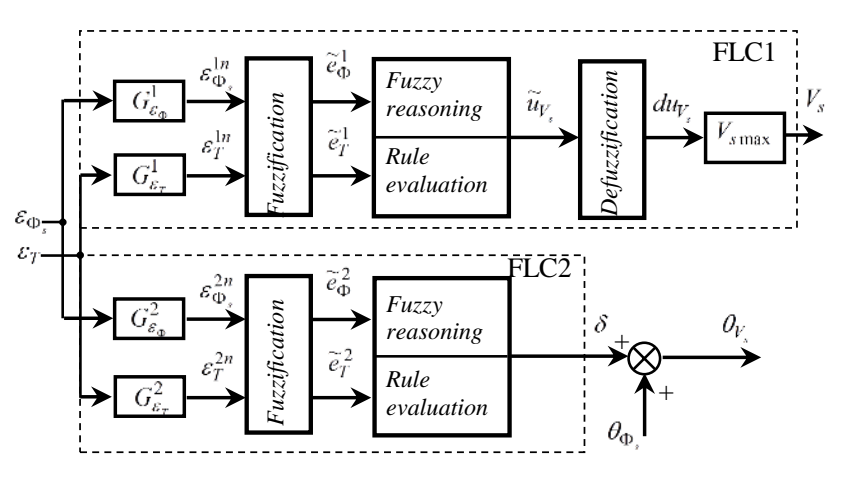

Fig. 7. Fuzzy logic controller structure

\section{Simulation Results}

Two models based on Matlab environment were developed to examine the different control algorithm. One is used for the conventional DTC and the other for the modified DTC. The parameters of the induction motor are listed in Appendix 1.

The behavior of the PMSM motor with conventional DTC and fuzzy DTC are illustrated in Figure 8.

Figure 8 shows the speed, torque, current and flux responses for the conventional DTC and fuzzy DTC control. The motor operates at $\omega_{m}=600 \mathrm{rad} / \mathrm{s}$. By comparing the two figures, we notice that the proposed method reduces the torque ripple to almost $80 \%$. The poor torque control capability of the conventional method is caused by the large time for the active voltage vector application, which is higher than necessary to control the torque accurately.

The simulation results show that the proposed DTC system has less torque ripple while maintaining a good torque response as compared to the conventional DTC method.

\section{Conclusion}

This paper presents a fuzzy direct torque control strategy for PMSM that achieves constant switching frequency and reduced torque ripple control. The proposed DTC method uses the stator flux amplitude and the electromagnetic torque errors through two fuzzy logic controllers to generate a voltage space vector by acting on both the amplitude and the angle of its components, which is used by a space vector modulation to provide the inverter switching states. By this method, torque ripple is smaller than that of conventional DTC. Comparisons through simulations with conventional DTC have been carried out. The results obtained show clearly that the proposed DTC reduces the torque and flux ripples drastically while still having a good dynamic torque response which is one of the main characteristic performances of DTC method.

\section{Appendix 1}

\begin{tabular}{ll}
\hline \hline Resistance & $0,03 \Omega$ \\
$d$-axis inductance & $0,2 \mathrm{mH}$ \\
$q$-axis inductance & $0,2 \mathrm{mH}$ \\
Permanent magnet flux & $0,08 \mathrm{~Wb}$ \\
Pole pairs & 4 \\
\hline \hline
\end{tabular}

Table 5. The specifications of motors

\section{References}

[1] I. Takahashi and T. Naguchi, "A new quick-response and higheffeciency control strategy of an induction motor", IEEE Trans. Ind. Appl., vol. IA-22, pp. 820-827, Sep./Oct. 1986.

[2] D. Casadei, G. Grandi, G. Serra and A. Tani, "Effects of flux and torque hysteresis band amplitude in direct torque control of induction machine", in Proc. IECON'94 Bologna, Italy, Sep. 59, 1994, pp. 299-304.

[3] G.S. Buja and M.P. Kazmierkowski, "Direct torque control of PWM Inverter-Fed AC motors - A survey", IEEE Trans. On Ind. Electronics, vol. 51, no. 4, pp. 744-757, August 2002.

[4] Yen Shin Lai, Jian Ho Chen, "A new approach to direct torque control of induction motor drives for constant inverter switching frequency and torque ripple reduction", IEEE Trans. Energy Conversion, vol. E-40, no. 2, pp. 325-331, Mars. 2001.

[5] P. Pragason, R. Krishnan, "Modelling, simulation and modelling of permanent magnet synchronous motor drive", IEEE Trans. On Ind. Appl., vol. 25, no. 2, pp. 265-273, 1989.

[6] Bimal K. Bose, "Modern power electronics and AC drives [M]", Beijing. Machine Press 2004.

[7] M. Vasudevan and R. Arumugam, "New direct torque control scheme of induction motor for electric vehicle", $5^{\text {th }}$ Asian control conference, pp. 1377-1383, 2004.

[8] A. Kumar, B.G. Fernandes and K. Chatterjee, "Simplified SVPWM-DTC of 3-phase induction motor using the concept of imaginary switching times", The $30^{\text {th }}$ Annual conference of the IEEE Ind. Electronics society, Korea, pp. 341-346, 2004.

[9] U. Senthil and B.G. Fernandes, "Hybrid space vector pulse with modulation based direct torque controlled induction motor drive", IEEE'02, vol. 3 pp. 1112-1117, 2003.

[10] Cao, Xianqing, Zang, Chunhua, Fan, Liping, "Direct Torque Controlled Drive for Permanent Magnet Synchronous Motor Based on Neural Networks and Multi Fuzzy Controllers", IEEE International Conference on Robotics and Biomimetics, 2006. ROBIO '06. pp. $197-201,2006$. 
[11] T. Chapuis, D. Roy, S. Courtine. "Commande directe du couple d'une machine asynchrone par le contrôle direct de son flux statorique”, Journal de physique III n6, France, Juin 1995.

[12] M. Vasudevan, R. Arumugam, "New direct torque control scheme of induction motor for electric vehicles", 5th Asian Control Conference, vol. 2, 20-23, pp. 1377 - 1383, 2004.

[13] L. Youb, A. Craciunescu, “A comparison of various strategies for direct torque control of induction motors", Electrical Machines and Power Electronics, ACEMP '07. International Aegean Conference on Digital Object Identifier, pp. 403-408, 2007.

[14] Y. Inoue, S. Morimoto, M. Sanada, "Examination and Linearization of Torque Control System for Direct Torque Controlled IPMSM", Industry Applications, IEEE Transactions on Digital Object Identifier, vol. 46, n .01, pp. 159-166, 2010.
[15] Zhijun Jiang, Shimiao Hu, Wenhui Cao, “A New Fuzzy Logic Torque Control Scheme Based on Vector Control and Direct Torque Control for Induction Machine", Innovative Computing Information and Control, ICICIC '08. 3rd International Conference on Digital Object Identifier, pp. 500-500, 2008.

[16] M.A. Said, M.F.M. Elias, P. Hew Wooi, N.A. Rahim, "Switching-table and space vector modulation direct torque control of permanent magnet synchronous motor drives simulation", Technical Postgraduates (TECHPOS), 2009 International Conference for Digital Object Identifier, pp. 1-4, 2009.

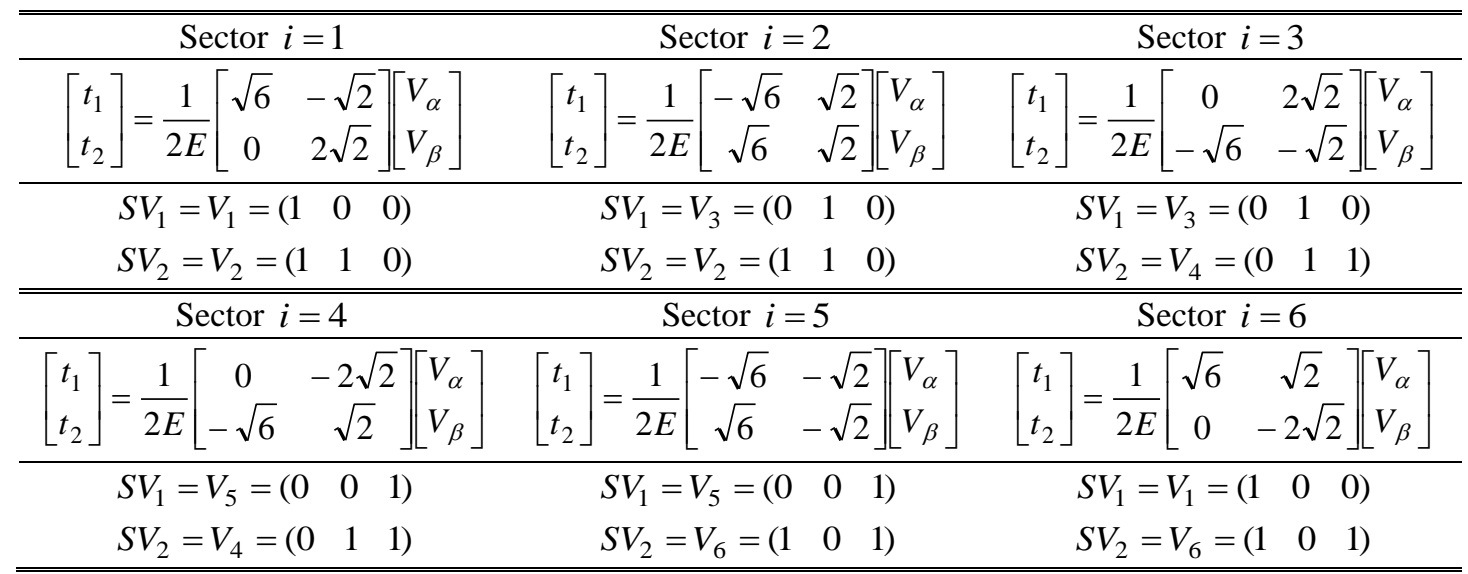

Table 4. SVM during switching vectors and duty cycles 
PMSM DTC SYSTEM

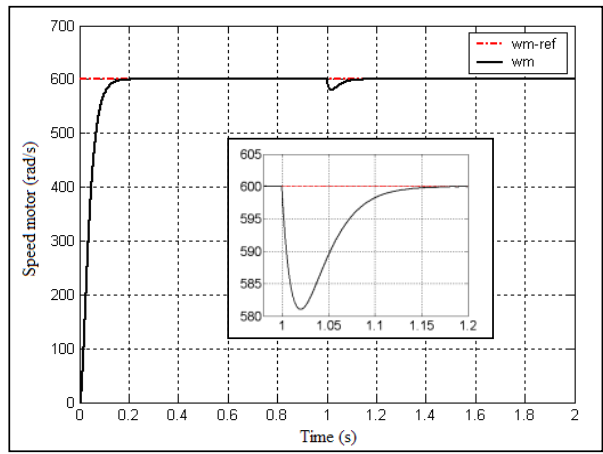

(a) Speed motor

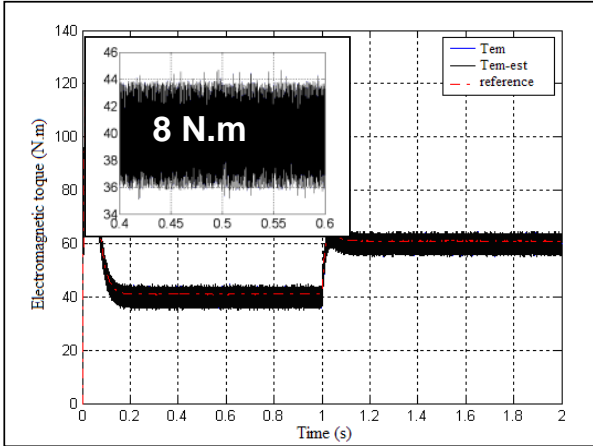

(b) Electromagnetic torque

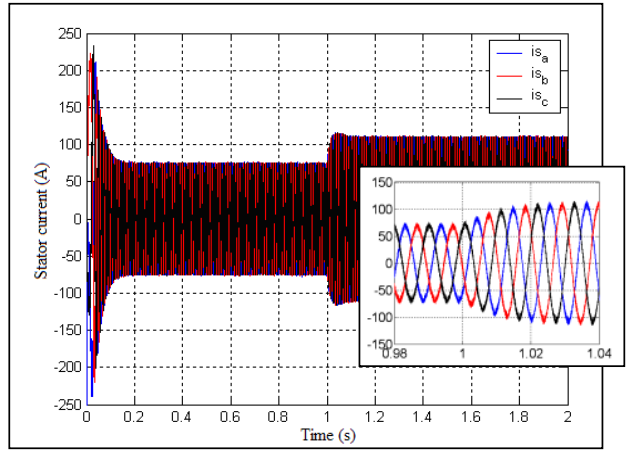

(c) Phase current

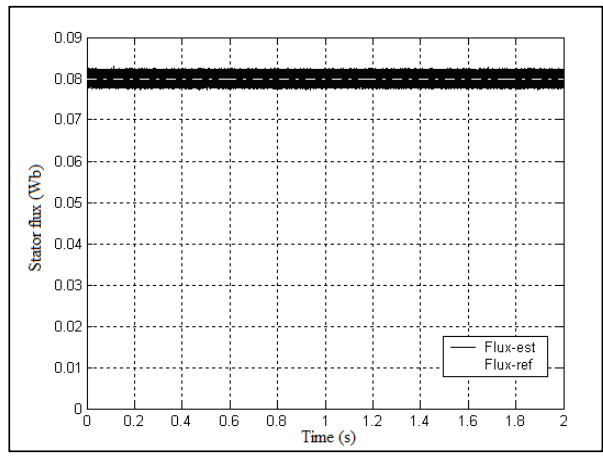

(d) Stator flux linkage
PMSM FUZZY DTC SYSTEM

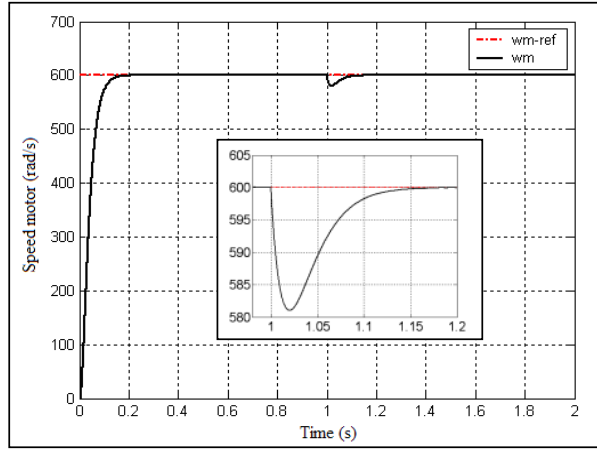

(a) Speed motor

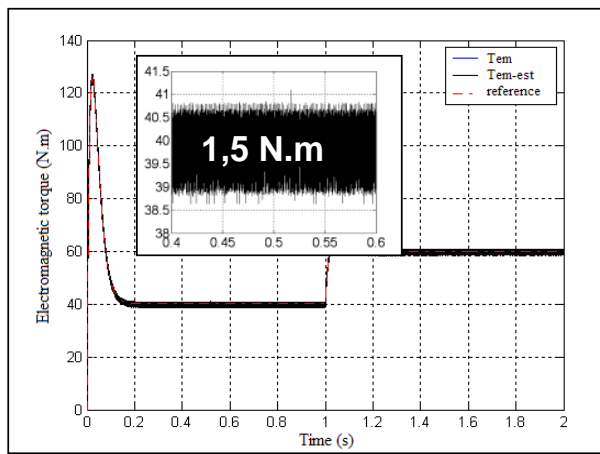

(b) Electromagnetic torque

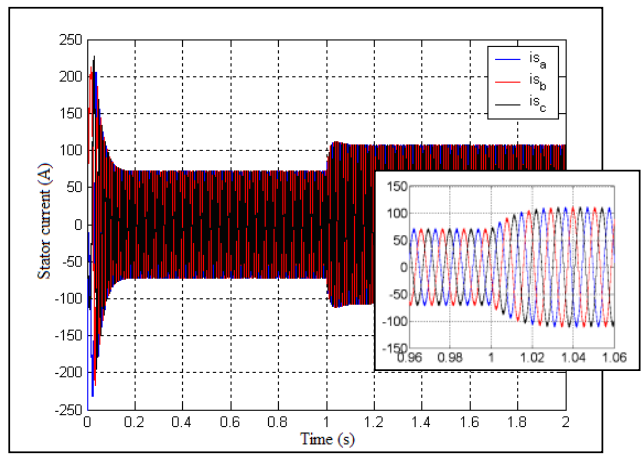

(c) Phase current

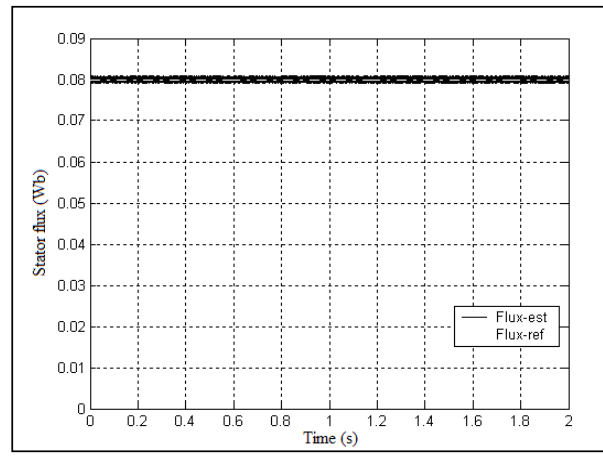

(d) Stator flux linkage

Fig. 8 Comparative Simulation results 